\title{
Educação escolar e cultura(s): construindo caminhos
}

\author{
Antonio Flavio Barbosa Moreira \\ Universidade Católica de Petrópolis, Mestrado em Educação
}

Vera Maria Candau

Pontifícia Universidade Católica do Rio de Janeiro, Departamento de Educação

\section{Introdução}

Em inúmeros momentos de trabalho com docentes de redes estaduais e municipais, em diferentes cidades do país, temos sido confrontados com perguntas que nos evidenciam a dificuldade presente entre $o$ professorado, tanto de tornar a cultura um eixo central do processo curricular, como de conferir uma orientação multicultural às suas práticas. São freqüentes, nesses encontros, indagações relativas ao(à) aluno(a) concreto(a) que usualmente está presente na sala de aula: como lidar com essa criança tão "estranha", que apresenta tantos problemas, que tem hábitos e costumes tão "diferentes" dos da criança "bem educada"? Como "adaptá-la" às normas, condutas e valores vigentes? Como ensinar-lhe os conteúdos que se encontram nos livros didáticos? Como prepará-la para os estudos posteriores? Como integrar a sua experiência de vida de modo coerente com a função específica da escola?

Tais questões refletem visões de cultura, escola, ensino e aprendizagem que não dão conta, a nosso ver, dos desafios encontrados em uma sala de aula "invadida" por diferentes grupos sociais e culturais, antes ausentes desse espaço. Não dão conta, acreditamos, do inevitável caráter multicultural das sociedades contemporâneas, nem respondem às contradições e às demandas provocadas pelos processos de globalização econômica e de mundialização da cultura (Ortiz, 1994), que tanto têm intensificado a cisão do mundo em "ricos" e "pobres", "civilizados" e "selvagens", "nós" e "eles", "incluídos" e "excluídos".

Ao mesmo tempo em que se expressam dificuldades e dúvidas por parte de muitos docentes, significativas experiências têm sido desenvolvidas, tanto no âmbito das escolas como de outros espaços de educação não formal, propondo-se a transcender o pluralismo "benigno" de visões correntes de multiculturalismo e a afirmar as vozes e os pontos de vista de minorias étnicas e raciais marginalizadas e de homens e mulheres das camadas populares. Todavia, a despeito das conquistas e das contribuições dessas experiências, ainda não podemos considerar que uma orientação multicultural numa perspectiva emancipatória (Sousa Santos, 2003) costume nortear as práticas curriculares das escolas e esteja presente, de 
modo significativo, nos cursos que formam os docentes que nelas ensinam.

Estamos ainda distante do que Connell (1993) denomina de justiça curricular, pautada, a seu ver, por três princípios: (a) os interesses dos menos favorecidos, (b) participação e escolarização comum e (c) a produção histórica da igualdade. Para o autor, o critério da justiça curricular é o grau em que uma estratégia pedagógica produz menos desigualdade no conjunto de relações sociais ao qual o sistema educacional está ligado. Considerando as especificidades e a complexidade do panorama social e cultural deste início de século, sugerimos que a concepção de justiça curricular se amplie e se compreenda como a proporção em que as práticas pedagógicas incitam o questionamento às relações de poder que, no âmbito da sociedade, contribuem para criar e preservar diferenças e desigualdades. Quer-se favorecer, como conseqüência, a redução, na escola e no contexto social democrático, de atos de opressão, preconceito e discriminação.

Entendemos diferença como McCarthy (1998), que a define como o conjunto de princípios que têm sido empregados nos discursos, nas práticas e nas políticas para categorizar e marginalizar grupos e indivíduos. Defendemos, ainda, o ponto de vista de que, particularmente em um país como o Brasil, não é possível nos esquecermos da desigualdade e nos voltarmos apenas para as diferenças entre os indivíduos. Não cabe, portanto, abandonarmos a idéia de totalidade (García Canclini, 1990). Apoiando-nos em Sousa Santos (2001, 2003), insistimos na necessidade de uma orientação multicultural, nas escolas e nos currículos, que se assente na tensão dinâmica e complexa entre políticas da igualdade e políticas da diferença. "As versões emancipatórias do multiculturalismo baseiam-se no reconhecimento da diferença e do direito à diferença e da coexistência ou construção de uma vida em comum além de diferenças de vários tipos" (Santos, 2003, p. 33).

Construir o currículo com base nessa tensão não é tarefa fácil e irá certamente requerer do professor nova postura, novos saberes, novos objetivos, novos conteúdos, novas estratégias e novas formas de avaliação. Será necessário que o docente se disponha e se capacite a reformular o currículo e a prática docente com base nas perspectivas, necessidades e identidades de classes e grupos subalternizados.

Tais mudanças nem sempre são compreendidas e vistas como desejáveis e viáveis pelo professorado. Certamente, em muitos casos, a ausência de recursos e de apoio, a formação precária, bem como as desfavoráveis condições de trabalho constituem fortes obstáculos para que as preocupações com a cultura e com a pluralidade cultural, presentes hoje em muitas propostas curriculares oficiais (alternativas ou não), venham a se materializar no cotidiano escolar. Mas, repetimos, não se trata de uma tarefa suave.

Nosso texto pretende, com base em resultados de pesquisas que coordenamos e de teorizações que temos analisado, oferecer subsídios para que essa tarefa venha a ser mais bem enfrentada. Pretende ir além da intenção de dialogar com os pares da academia e visa a apresentar princípios, exemplos e sugestões que possam ser úteis ao professorado em seu empenho por tornar a cultura elemento central de seus planos e suas práticas. Não pretende oferecer prescrições. Nosso propósito é outro: estimular nossos colegas a construírem e desenvolverem novos currículos de forma autônoma, coletiva e criativa. Julgamos ser possível e desejável que as pesquisas realizadas no âmbito das universidades, principalmente as que se desenvolvem sobre e com a escola, possam catalisar experiências que tornem o cotidiano escolar não o espaço da rotina e da repetição, mas o espaço da reflexão, da crítica, da rebeldia, da justiça curricular. Mais uma vez recorrendo a Connell (1993), julgamos que, se os currículos continuarem a produzir e a preservar divisões e diferenças, reforçando a situação de opressão de alguns indivíduos e grupos, todos, mesmo os membros dos grupos privilegiados, acabarão por sofrer. A consequiência poderá ser a degradação da educação oferecida a todos os estudantes.

Sem pretender esgotar os desafios e as possibilidades envolvidas nas temáticas em pauta, estruturamos o texto de modo a discutir, inicialmente, como 
se deve entender hoje a centralidade da cultura na sociedade e na educação. A seguir, enfocamos as relações entre escola e cultura(s). Em terceiro lugar, sugerimos estratégias pedagógicas que possam ser úteis para a abordagem da diversidade e da pluralidade cultural no currículo. Finalmente, apresentamos nossas considerações finais, trazendo à cena alguns desafios envolvidos na formação dos(as) professores(as) que venham a considerar as questões culturais contemporâneas no desenvolvimento de suas práticas docentes.

\section{A centralidade da cultura}

A importância da cultura no mundo contemporâneo tem sido enfatizada por autores de diferentes tendências. No âmbito do pensamento pós-moderno, a cultura adquire cada vez mais um papel mais significativo na vida social: hoje, tudo chega mesmo a ser visto como cultural (Baudrillard, apud Featherstone, 1997). A cultura estaria, assim, além do social, descentralizando-se, livrando-se de seus determinismos tradicionais na vida econômica, nas classes sociais, no gênero, na etnicidade e na religião. Segundo Featherstone, no entanto, trata-se, na verdade, de uma recentralização da cultura, expressa no aumento da importância atribuída ao estudo da cultura no âmbito da vida acadêmica. A cultura, há muito situada na periferia do campo das ciências sociais, tem-se movido em direção ao centro, o que talvez se explique pela tendência mais ampla de enfraquecimento das divisões entre as áreas de estudo e de intensificação de estudos inter e transdisciplinares. Para Featherstone, em síntese, a descentralização mais geral da cultura tem sido acompanhada por sua recentralização na vida acadêmica.

No campo da educação, Michael Apple (1999), um dos mais renomados autores da teoria crítica do currículo, sustenta que lutas e conflitos culturais não constituem meros epifenômenos, mas sim eventos reais e cruciais na batalha por hegemonia. Desse modo, as explicações centradas na cultura, na política e na ideologia assumem hoje papel de destaque no cenário social, adicionando-se às análises dos fenômenos complexos e contraditórios que se desenvolvem no nível econômico. Apple acrescenta, todavia, que valorizar e reconhecer a importância da esfera cultural não pode implicar a desconsideração da força do capitalismo, do caráter determinante das relações de produção e do poder da classe social. Isso seria, insiste o autor, um grave erro.

A centralidade da cultura é também destacada pelos autores associados ao marxismo culturalista, entre os quais se destacam Raymond Williams e Edward Thompson. Para esses teóricos, o modelo base-superestrutura, proposto pelo marxismo ortodoxo, transforma a história em um processo automático e a cultura em um domínio de idéias e significados restritos a um mero reflexo da estrutura econômica da sociedade. Nesse enfoque, a cultura reduz-se a um epifenômeno, secundarizando-se as tensões, mediações e experiências dos seres humanos reais (Giroux, 1983).

Assim, no âmbito do marxismo culturalista, a centralidade da cultura é também enfatizada. Considera-se que a cultura não se aparta das atividades características e das interações da vida cotidiana, o que implica o reconhecimento da importância das ações e das experiências dos indivíduos nas análises dos fenômenos sociais. Para Giroux (1983), a despeito da supervalozição das experiências vividas, o marxismo culturalista traz à tona os equívocos envolvidos na visão da cultura como mero reflexo da infra-estrutura, bem como propicia uma visão mais abrangente e profunda da esfera cultural da sociedade, na qual os indivíduos atuam em meio a práticas e a conflitivas relações de poder, produzindo, rejeitando e compartilhando significados. É essa visão que se difunde e se amplia no seio dos Estudos Culturais, que têm em Stuart Hall um dos autores de maior proeminência.

Em marcante artigo, Hall (1997) reafirma a centralidade da cultura no cenário contemporâneo e ressalta seu papel constitutivo em todos os aspectos da vida social. Para o autor, estamos mesmo diante de uma revolução cultural, evidenciada pela significativa expansão do domínio configurado por instituições 
e práticas culturais. Além disso, os meios de produção, circulação e troca cultural também se ampliam, graças ao desenvolvimento da tecnologia, particularmente da informática. Em suas palavras:

A velha distinção que o marxismo clássico fazia entre a "base" econômica e a "superestrutura" ideológica é de difícil sustentação nas atuais circunstâncias em que a mídia é, ao mesmo tempo, uma parte crítica na infra-estrutura material das sociedades modernas, e, também, um dos principais meios de circulação das idéias e imagens vigentes nestas sociedades. (p. 17)

As transformações culturais desenvolvem-se também de forma bastante aguda no nível do microcosmo. A expressão "centralidade da cultura", tal como empregada por Hall, refere-se exatamente à forma como a cultura penetra em cada recanto da vida social contemporânea, tornando-se elemento-chave no modo como o cotidiano é configurado e modificado. Assim, a cultura não pode ser estudada como variável sem importância, secundária ou dependente em relação ao que faz o mundo se mover, devendo, em vez disso, ser vista como algo fundamental, constitutivo, que determina a forma, o caráter e a vida interior desse movimento. Reiteram-se, pode-se observar, pontos já enfatizados por autores como Williams e Thompson.

Além da centralidade da cultura na ascensão de novos domínios, instituições e tecnologias associadas às indústrias culturais, na mudança histórica global, assim como na transformação do cotidiano, Hall realça o lugar central ocupado pela cultura no processo de formação de identidades sociais. Para ele:

O que denominamos "nossas identidades" poderia provavelmente ser melhor conceituado como as sedimentações através do tempo daquelas diferentes identificações ou posições que adotamos e procuramos "viver", como se viessem de dentro, mas que, sem dúvida, são ocasionadas por um conjunto especial de circunstâncias, sentimentos, histórias e experiências únicas e peculiarmente nossas, como sujeitos individuais. Nossas identidades são, em resumo, formadas culturalmente. (p. 26)
Aos aspectos já mencionados, Hall acrescenta a presença significativa de aspectos epistemológicos na virada cultural. No interior dessa virada, passa-se a privilegiar determinados temas na análise de fenômenos sociais, alça-se cultura à condição de categoria essencial para o esforço de se compreender a vida e a organização da sociedade, estabelece-se a matriz intelectual que propiciou a eclosão dos Estudos Culturais, bem como modificam-se práticas acadêmicas hegemônicas.

$\mathrm{O}$ autor procura esclarecer, ao mesmo tempo, que o posicionamento a favor da centralidade da cultura não implica considerar que nada exista a não ser a cultura. Significa, sim, admitir que toda prática social tem uma dimensão cultural, já que toda prática social depende de significados e com eles está estreitamente associada. A esfera econômica, por exemplo, não funcionaria nem teria qualquer efeito fora da cultura e dos significados. Economia e cultura constituem-se mutuamente, articulam-se. Certamente essa ressalva é valiosa, por permitir que se evitem interpretações apressadas, com base nas quais se acusem Hall e os demais autores dos Estudos Culturais de reducionismo.

O que de fato Hall argumenta é que toda prática social depende do significado e com ele tem relação. A cultura é uma das condições constitutivas de existência dessa prática, o que faz com que toda prática social tenha uma dimensão cultural. Aceitando-se esse ponto de vista, não há como se negar a estreita relação entre as práticas escolares e a(s) cultura(s).

\section{Escola e cultura(s)}

A problemática das relações entre escola e cultura é inerente a todo processo educativo. Não há educação que não esteja imersa na cultura da humanidade e, particularmente, do momento histórico em que se situa. A reflexão sobre esta temática é co-extensiva ao próprio desenvolvimento do pensamento pedagógico. Não se pode conceber uma experiência pedagógica "desculturizada", em que a referência cultural não esteja presente. 
A escola é, sem dúvida, uma instituição cultural. Portanto, as relações entre escola e cultura não podem ser concebidas como entre dois pólos independentes, mas sim como universos entrelaçados, como uma teia tecida no cotidiano e com fios e nós profundamente articulados. Se partimos dessas afirmações, se aceitamos a íntima associação entre escola e cultura, se vemos suas relações como intrinsecamente constitutivas do universo educacional, cabe indagar por que hoje essa constatação parece se revestir de novidade, sendo mesmo vista por vários autores como especialmente desafiadora para as práticas educativas.

A escola é uma instituição construída historicamente no contexto da modernidade, considerada como mediação privilegiada para desenvolver uma função social fundamental: transmitir cultura, oferecer às novas gerações o que de mais significativo culturalmente produziu a humanidade. Essa afirmação suscita várias questões: Que entendemos por produções culturais significativas? Quem define os aspectos da cultura, das diferentes culturas que devem fazer parte dos conteúdos escolares? Como se têm dado as mudanças e transformações nessas seleções? Quais os aspectos que têm exercido maior influência nesses processos? Como se configuram em cada contexto concreto?

Segundo Gimeno Sacristán (2001, p. 21),

A educação contribuiu consideravelmente para fundamentar e para manter a idéia de progresso como processo de marcha ascendente na História; assim, ajudou a sustentar a esperança em alguns indivíduos, em uma sociedade, em um mundo e em um porvir melhores. A fé na educação nutre-se da crença de que esta possa melhorar a qualidade de vida, a racionalidade, o desenvolvimento da sensibilidade, a compreensão entre os seres humanos, o decréscimo da agressividade, o desenvolvimento econômico, ou o domínio da fatalidade e da natureza hostil pelo progresso das ciências e da tecnologia propagadas e incrementadas pela educação. Graças a ela, tornou-se possível acreditar na possibilidade de que o projeto ilustrado pudesse triunfar devido ao desenvolvimento da inteligência, ao exercício da racionalidade, à utilização do conhecimento científico e à geração de uma nova ordem social mais racional.
Essa é a utopia que impregnou e impregna ainda hoje a educação escolar. Esse tem sido, sinteticamente, seu horizonte de sentido. É esse o modelo cultural que vem perpassando, no meio de tensões e conflitos, o seu cotidiano. Tal modelo seleciona saberes, valores, práticas e outros referentes que considera adequados ao seu desenvolvimento. Assenta-se sobre a idéia da igualdade e do direito de todos e todas à educação e à escola.

No entanto, numerosos estudos e pesquisas têm evidenciado como essa perspectiva termina por veicular uma visão homogênea e padronizada dos conteúdos e dos sujeitos presentes no processo educacional, assumindo uma visão monocultural da educação e, particularmente, da cultura escolar. Essa nos parece ser uma problemática cada vez mais evidente. O que está em questão, portanto, é a visão monocultural da educação. Os "outros", os "diferentes" - os de origem popular, os afrodescendentes, os pertencentes aos povos originários, os rappers, os funkeiros etc. -, mesmo quando fracassam e são excluídos, ao penetrarem no universo escolar desestabilizam sua lógica e instalam outra realidade sociocultural.

Essa nova configuração das escolas expressa-se em diferentes manifestações de mal-estar, em tensões e conflitos denunciados tanto por educadores(as) como por estudantes. É o próprio horizonte utópico da escola que entra em questão: os desafios do mundo atual denunciam a fragilidade e a insuficiência dos ideais "modernos" e passam a exigir e suscitar novas interrogações e buscas. A escola, nesse contexto, mais que a transmissora da cultura, da "verdadeira cultura", passa a ser concebida como um espaço de cruzamento, conflitos e diálogo entre diferentes culturas.

Pérez Gómez (1998) propõe que entendamos hoje a escola como um espaço de "cruzamento de culturas". Tal perspectiva exige que desenvolvamos um novo olhar, uma nova postura, e que sejamos capazes de identificar as diferentes culturas que se entrelaçam no universo escolar, bem como de reinventar a escola, reconhecendo o que a especifica, identifica e distingue de outros espaços de socialização: a "mediação reflexiva" que realiza sobre as interações e o 
impacto que as diferentes culturas exercem continuamente em seu universo e seus atores.

Conforme o mesmo autor:

O responsável definitivo da natureza, sentido e consistência do que os alunos e alunas aprendem na sua vida escolar é este vivo, fluido e complexo cruzamento de culturas que se produz na escola entre as propostas da cultura crítica, que se situa nas disciplinas científicas, artística e filosóficas; as determinações da cultura acadêmica, que se refletem no currículo; as influências da cultura social, constituídas pelos valores hegemônicos do cenário social; as pressões cotidianas da cultura institucional, presente nos papéis, normas, rotinas e ritos próprios da escola como instituição social específica, e as características da cultura experiencial, adquirida por cada aluno através da experiência dos intercâmbios espontâneos com seu entorno. (Pérez Gómez, 1998, p. 17)

O que caracteriza o universo escolar é a relação entre as culturas, relação essa atravessada por tensões e conflitos. Isso se acentua quando as culturas crítica, acadêmica, social e institucional, profundamente articuladas, tornam-se hegemônicas e tendem a ser absolutizadas em detrimento da cultura experiencial, que, por sua vez, possui profundas raízes socioculturais.

Em vez de preservar uma tradição monocultural, a escola está sendo chamada a lidar com a pluralidade de culturas, reconhecer os diferentes sujeitos socioculturais presentes em seu contexto, abrir espaços para a manifestação e valorização das diferenças. É essa, a nosso ver, a questão hoje posta. A escola sempre teve dificuldade em lidar com a pluralidade e a diferença. Tende a silenciá-las e neutralizá-las. Sente-se mais confortável com a homogeneização e a padronização. No entanto, abrir espaços para a diversidade, a diferença, e para o cruzamento de culturas constitui o grande desafio que está chamada a enfrentar.

\section{Escola, cultura e diversidade cultural: estratégias pedagógicas}

Abordaremos alguns aspectos especialmente significativos na tentativa de promover, no contexto es- colar, práticas educativas sensíveis a essas questões. Privilegiaremos duas dimensões: (a) diversidade cultural e currículo, (b) o combate à discriminação e ao racismo no cotidiano escolar.

\section{Diversidade cultural e currículo}

Em recente pesquisa, ${ }^{1}$ foram entrevistados sete pesquisadores(as) brasileiros(as) cujo objeto de estudo é o multiculturalismo. Todos(as) mostraram-se associados(as) ao que se pode chamar de multiculturalismo crítico (Stoer \& Cortesão, 1999), correspondente a uma perspectiva emancipatória que envolve, além do reconhecimento da diversidade e das diferenças culturais, a análise e o desafio das relações de poder sempre implicadas em situações em que culturas distintas coexistem no mesmo espaço. Para todos(as), uma ação docente multiculturalmente orientada, que enfrente os desafios provocados pela diversidade cultural na sociedade e nas salas de aulas, requer uma postura que supere o "daltonismo cultural" usualmente presente nas escolas, responsável pela desconsideração do "arco-íris de culturas" com que se precisa trabalhar. Requer uma perspectiva que valorize e leve em conta a riqueza decorrente da existência de diferentes culturas no espaço escolar.

Além da superação do daltonismo cultural, nossos(as) especialistas sugerem estratégias pedagógicas que permitam lidar com essa heterogeneidade. Destacamos algumas, sem esgotá-las, complementando-as com pontos de vista e sugestões que se encontram na literatura especializada sobre multiculturalismo.

Inicialmente, ressaltamos o que uma das especialistas afirmou:

Temos que reescrever o conhecimento a partir das diferentes raízes étnicas. Mas não é cada um fechadinho no

1 "O multiculturalismo e o campo do currículo no Brasill", sob a coordenação de Antonio Flavio Barbosa Moreira e com a participação de docentes e discentes da UFRJ e da UERJ. Nas transcrições, optamos por não identificar os(as) entrevistados(as). 
seu canto. Eu tenho que reescrever a partir da minha experiência nessa raiz étnica. É a experiência vivida, inclusive no nosso caso, dos descendentes de africanos na diáspora. $\mathrm{O}$ conhecimento tem que ser reescrito e reescrito a partir daí.

Tal comentário coincide com os argumentos apresentados por McCarthy (1998), em sua discussão sobre o processo de hibridização cultural. Segundo o autor, é essencial que nos situemos, na prática pedagógica multicultural, além da visão das culturas como interrelacionadas, como mutuamente geradas e influenciadas, e procuremos facilitar a compreensão do mundo pelo olhar do subalternizado. Para o currículo, trata-se de desestabilizar o modo como o outro é mobilizado e representado. "O olhar do poder, suas normas e pressupostos, precisa ser desconstruído" (McCarthy, 1998, p. 156). Trata-se de desafiar a pretensa estabilidade e o caráter aistórico do conhecimento produzido no mundo ocidental, segundo a ótica do dominante, e confrontar diferentes perspectivas, diferentes pontos de vista, diferentes obras literárias, diferentes interpretações dos eventos históricos, de modo a favorecer ao(à) aluno(a) entender como o conhecimento tem sido escrito de uma dada forma e como pode ser reescrito de outra forma. Trata-se, em última análise, não de substituir um conhecimento por outro, mas sim de propiciar aos(às) estudantes a compreensão das conexões entre as culturas, das relações de poder envolvidas na hierarquização das diferentes manifestações culturais, assim como das diversas leituras que se fazem quando distintos olhares são privilegiados.

Em segundo lugar, pode ser relevante atentarmos para o que nos propõe uma outra especialista entrevistada na pesquisa em pauta. Ela sugere a "ancoragem social" dos conteúdos.

Ancorar socialmente o conteúdo: ver como é que ele surgiu, em que contexto social ele surgiu, quem foi que propôs historicamente esse conceito, quais eram as ideologias dominantes. E aí você vai fazendo isso com todos os conteúdos possíveis dentro do currículo e [...] isso é uma maneira de você nem cair naquele vazio de ficar só tentando entender diversas linguagens, diversas culturas, e também não cair na idéia de que o conteúdo é algo fixo. É uma outra vertente.

Ou seja, o que a pesquisadora defende é que se evidencie com clareza, no currículo, como se construiu historicamente um dado conhecimento, como as raízes históricas e culturais desse processo são usualmente "esquecidas", o que faz com que todo e qualquer conhecimento (usualmente pautado na lógica dominante nos países centrais) seja visto como indiscutível, neutro, universal, intemporal. Nessa mesma direção, pode-se acentuar a necessidade de se explicitar, também, como um dado conhecimento relaciona-se com os eventos e as experiências dos(as) estudantes e do mundo concreto, enfatizando-se ainda, na discussão, quem lucra e quem perde com as formas de emprego do conhecimento. Em síntese, os propósitos, nas duas propostas até aqui apresentadas, parecem ser clarificar de quem é o conhecimento hegemônico no currículo, que representações estão nele incluídas, que identidades se deseja que eles reflitam e construam, assim como explorar formas de desestabilizar e desafiar todas essas hierarquias, escolhas, inclusões, imagens e pontos de vista.

Uma proposta que caminha no mesmo sentido da ancoragem social e que particularmente nos agrada é a de Willinsky (1998). O autor sugere que nos perguntemos se é possível dividir a realidade humana em culturas, raças, histórias, tradições e sociedades claramente diferentes, e sobrevivermos dignamente às conseqüências dessas classificações. Insiste, então, no questionamento do caráter aparentemente natural, às vezes mesmo científico, dessas divisões. É indispensável, acrescenta, compreendermos a dinâmica histórica das categorias por meio das quais somos rotulados, identificados, definidos e situados na estrutura social. Esse entendimento será favorecido ao focalizarmos, no currículo, a construção das categorias, ao lutarmos por mudar seus significados e por garantir espaço na escola e na sala de aula para a diversidade.

Ou seja, Willinsky rejeita a idéia de que existe uma verdade, uma essência ou um núcleo em qualquer categoria. Incentiva-nos a, nas diferentes disciplinas 
curriculares, tornar evidente e contestar a construção histórica de categorias que nos têm marcado, como raça, nação, sexualidade, masculinidade, feminilidade, idade etc. Com essa estratégia, pretende facilitar a compreensão de como o mundo tem sido dividido.

Em terceiro lugar, propomos que se expandam os conteúdos curriculares usuais, de modo a neles incluir a crítica dos diferentes artefatos culturais que circundam o(a) aluno(a). A idéia é transformar a escola em um espaço de crítica cultural, de modo que cada professor(a), como intelectual que é, possa desempenhar o papel de crítico(a) cultural (Sarlo, 1999) e propiciar ao(à) estudante a compreensão de que tudo que passa por "natural" e "inevitável" precisa ser questionado e pode, conseqüentemente, ser transformado. A idéia é favorecer novos patamares que permitam uma renovada e ampliada visão daquilo com que usualmente lidamos de modo acrítico. Nesse sentido, filmes, anúncios, modas, costumes, danças, músicas, revistas, espaços urbanos etc. precisam adentrar as salas de aulas e constituir objetos da atenção e da discussão de docentes e discentes.

Nossa sugestão não implica, acrescentamos, que fiquemos limitados aos elementos usualmente secundarizados na hierarquia das culturas. Certamente eles precisam ser tratados e trabalhados nas salas de aula. Contudo, esperamos também que as manifestações culturais mais valorizadas socialmente venham a ser conhecidas, debatidas, criticadas e desconstruídas. Desejamos, além da crítica cultural, a expansão do horizonte cultural do(a) aluno(a) e o maior aproveitamento possível dos recursos culturais da comunidade em que a escola está inserida. Se reconhecemos a inexistência, no mundo contemporâneo, de qualquer "pureza cultural" (McCarthy, 1998), se pretendemos abrir espaço na escola para a complexa interpenetração das culturas e para a pluralidade cultural, garantindo a centralidade da cultura nas práticas pedagógicas, tanto as manifestações culturais hegemônicas como as subalternizadas precisam integrar o currículo, devendo ser confrontadas e desafiadas.

Abordamos, a seguir, estratégias específicas que, segundo a visão de profissionais da educação, podem ser capazes de desestabilizar atitudes de preconceito e discriminação.

\section{0 combate à discriminação e ao racismo no cotidiano escolar}

Uma das questões fundamentais de serem trabalhadas no cotidiano escolar, na perspectiva da promoção de uma educação atenta à diversidade cultural e à diferença, diz respeito ao combate à discriminação e ao preconceito, tão presentes na nossa sociedade e nas nossas escolas. Em recente pesquisa (Candau, 2003) realizada com o objetivo de identificar as diferentes manifestações do preconceito e da discriminação nesses espaços, foram claramente evidenciados os sutis processos de discriminação que permeiam nossas práticas sociais e educacionais em suas diversas dimensões.

Os dados levantados coincidem com a literatura sobre o tema, que afirma a existência de pluralidade de expressões de discriminação na sociedade brasileira, sendo a de caráter étnico (mais especificamente em relação ao segmento negro da população), bem como a discriminação social, as formas mais frequientemente apontadas. É importante salientar o caráter dialético da relação entre esses dois tipos de discriminação, o que faz com que um não possa ser reduzido ao outro.

A discriminação pode adquirir múltiplos rostos, referindo-se tanto a caráter étnico e caráter social, como a gênero, orientação sexual, etapas da vida, regiões geográficas de origem, características físicas e relacionadas à aparência, grupos culturais específicos (os funkeiros, os nerds etc.). Talvez seja possível afirmar que estamos imersos em uma cultura da discriminação, na qual a demarcação entre "nós" e "os outros" é uma prática social permanente que se manifesta pelo não reconhecimento dos que consideramos não somente diferentes, mas, em muitos casos, "inferiores", por diferentes características identitárias e comportamentos.

Muitos dos relatos sobre situações de discriminação mostraram, também, que a escola é palco de manifestações de preconceitos e discriminações de diversos tipos. No entanto, a cultura escolar tende a não reconhecê-los, já que está impregnada por uma 
representação padronizadora da igualdade - "aqui todos são iguais", "todos são tratados da mesma maneira" - e marcada por um caráter monocultural. Preconceitos e diferentes formas de discriminação estão presentes no cotidiano escolar e precisam ser problematizados, desvelados, desnaturalizados. Caso contrário, a escola estará a serviço da reprodução de padrões de conduta reforçadores dos processos discriminadores presentes na sociedade.

Convém salientar que os elementos discriminadores afetam distintas dimensões: o projeto políticopedagógico, o currículo explícito e o oculto, a dinâmica relacional, as atividades em sala de aula, o material didático, as comemorações e festas, a avaliação, a forma de se lidar com as questões de disciplina, a linguagem oral e escrita (as piadas, os apelidos, os provérbios populares etc.), os comportamentos não verbais (olhares, gestos etc.) e os jogos e as brincadeiras. É necessário ressaltar que expressões fortemente arraigadas no sentido comum, que expressam juízos de valor sobre determinados grupos sociais e/ ou culturais, assim como as brincadeiras, são âmbitos especialmente sensíveis às manifestações de discriminação no cotidiano escolar.

A problemática da discriminação é certamente complexa e precisa ser trabalhada com base em uma dimensão multidimensional. No entanto, questionar o "silêncio" que a aprisiona é fundamental. Falar abertamente sobre a discriminação com os(as) alunos(as), para alguns dos(as) professores(as) entrevistados(as), assumia quase um caráter antipedagógico. Outros(as), no entanto, consideraram ser muito importante enfrentar o assunto na sala de aula, precisamente para elucidar o sentido ideológico que o encobre.

Com a finalidade de identificar estratégias concretas de se trabalhar essas questões no cotidiano escolar, realizamos um grupo focal ${ }^{2}$ com professores(as)

2 "O grupo focal é um tipo especial de grupo em termos de finalidade, número de participantes, composição e procedimentos. O objetivo de um grupo focal é ouvir e coletar informação. Trata-se de um modo de se compreender melhor como as pessoas que já tinham uma trajetória de trabalho na perspectiva da educação multicultural e não discriminatória. O encontro teve a duração de aproximadamente duas horas. Participaram nove professores(as) da rede pública de ensino do estado do Rio de Janeiro, assim distribuídos(as): três coordenadores pedagógicos, duas diretoras e quatro docentes de diferentes áreas curriculares - um de história, uma de português, uma de ciências e uma de artes.

Para se trabalhar essa problemática na escola, os(as) professores(as) deram vários exemplos e apresentaram diferentes estratégias que incidem em diversas dimensões do cotidiano escolar. A primeira, ponto de partida para se caminhar na direção de uma educação multicultural e antidiscriminadora, implica reconhecer a existência dessa problemática, não silenciá-la, refletir sobre ela. O seguinte depoimento descreve uma situação concreta:

Um dia, numa reunião nossa de recreio, uma professora, mostrando fotos de final de semana, disse: "esta menina aqui, filha do meu colega, eles chamam ela de macaquinha”. Aí eu peguei depois as fotos e a macaquinha era negra e tinha muita criança branca, eu chamei-a e disse: "e esta aqui é galinhazinha, é patinho, qual o apelido de bicho dele?" "Ah!, não tem”. "Por quê? Por que a gente chama o pai de macaco e a filha de macaquinha?’[...] São questões que quando eu posso eu falo suave, mas quando eu não posso, sou incisiva...

Situações semelhantes a essa estão freqüentemente presentes no cotidiano escolar, mas são "naturalizadas". Ser capaz de questioná-las, trabalhar os incidentes críticos, favorecer uma reflexão sobre elas e revelar seu conteúdo discriminador e de negação do "outro" é fundamental.

pensam ou se sentem em relação a um tema, produto ou serviço. Os participantes são selecionados por terem algumas características em comum relacionadas com a temática do grupo focal" (Krueger \& Casey, 2000, p. 4). 
Outra iniciativa proposta pelos professores(as) relacionava-se ao trabalho coletivo:

Esta questão é de articulação mesmo. [...] há sempre um grupo de professores que por uma razão ou outra afinam mais com a idéia e trabalham juntos. Você não consegue mudar nada com uma pessoa caminhando sozinha, mas quando são três em parceria, pelo menos eles já vão e a escola vai, e nós conseguimos indiretamente A garotada vai muito com você, não tem jeito, organizar um processo em função disto.

Esse ponto foi reiterativamente assinalado pelos docentes. A construção de práticas multiculturais e não-discriminatórias só é possível na ação conjunta. A cultura escolar e a cultura da escola naturalizam com tanta força esses aspectos, que é somente no diálogo, no questionamento, no debate, que é possível desenvolver um novo olhar sobre o cotidiano escolar.

Outro tema que suscitou um amplo diálogo entre os educadores pode ser assim sintetizado: favorecer o desenvolvimento da auto-estima, do respeito e da valorização mútuos.

As crianças percebem tudo. Se eu tenho um professor negro e sou branco, se sou negro e o professor é branco e se o convívio ali é honesto, é sincero, há respeito mútuo, as crianças percebem. Se eu discrimino, de alguma forma, por qualquer coisa, ou por condição social, ou por raça, seja lá o que for, a criança percebe quando você trata seu aluno com carinho, afetividade e respeito. Eu escutei o seguinte discurso de um professor da escola. Tinha três alunos negros na porta da escola, no portão. Foi depois do feriado do dia da consciência negra. "Ontem eles comemoraram o dia deles, o Dia de Zebu”. Eu não acreditei no que estava ouvindo. “Ah! esqueci, Dia de Zumbi”. Os alunos em geral têm aversão a este professor. De vez em quando ele diz "aquele desgraçado", mesmo que ele não diga isso para o aluno, ele percebe. Isso aí, o exemplo, para mim, é fundamental.

Infelizmente, situações como essa são freqüentes no cotidiano escolar, também entre os(as) alunos(as). Como trabalhá-las, estimular dinâmicas de relacionamento, de reconhecimento mútuo, aceitação e valori- zação do "outro", diálogo intercultural, de modo a favorecer a construção de um autoconceito e uma autoestima positivos em todos(as) os(as) alunos(as) constitui uma preocupação fundamental para se desenrolarem práticas educativas multiculturais.

Essas questões não podem estar dissociadas do desenvolvimento do currículo. Ao contrário, devem estar profundamente articuladas com o modo por meio do qual cada escola constrói sua proposta curricular. A ancoragem social do currículo, já por nós mencionada, se faz indispensável:

É fundamental você associar ao seu conteúdo [...]. Você não deixa de dar a informação que todo ser humano precisa, não, mas você associa um conhecimento técnico e científico a uma questão social. [...] Como ia trabalhar a maçã de Newton caindo se os corpos que estavam caindo eram outros? Você associa força, um conceito físico, a força enquanto violência [...] se você trabalha a biodiversidade na matéria, você trabalha sociodiversidade. Eu tenho um livro - História de uma Folha -, um livro infantil, lindo, que conta a história de uma folha, a folha vai morrer, mas tem uma hora que pergunta "mas, por que somos diferentes e estamos na mesma árvore, por que há cores diferentes?” Aí esta pergunta é todo um trabalho que você pode fazer.

Nessa perspectiva, afetar o projeto político-pedagógico da escola se faz imprescindível:

O nosso trabalho tem de ser maior do que apagar incêndios, tem de ser um trabalho de construção, e dentro desta construção ele tem que respeitar princípios que precisam ser maiores, tem que ser uma coisa de instituição. É uma onda, porque, na verdade, é um trabalho de sedução, de convencimento, devagar e sempre, mas a escola tem de forçar a barra.

A escola tem um papel muito sério, inescapável, que é um espaço privilegiado de encontro com o diferente. A escola tem de ter um papel muito claro e verdadeiramente democrático, e a escola se democratiza quando ela garante os direitos e cobra os deveres de cada um e faz com que todos os alunos dali se respeitem. E aí eu insisto na construção de um projeto pedagógico que seja da escola e seja da Secretaria também, um projeto claro, porque o projeto pedagógico ele 
pensa a escola, ele pensa no todo, na sociedade. Ela tem que ser uma instituição que tem o objetivo no futuro.

Os(as) educadores(as) manifestaram estar conscientes de que se trata de um processo difícil, em muitos momentos desestabilizador, que suscita as mais variadas reações, que mexe com o imaginário coletivo, exige persistência, porque a própria cultura que nós temos nos convida a desistir no primeiro impasse. Trata-se de um grande desafio que supõe paciência para que a escola vá agregando estas idéias.

Os participantes do grupo focal identificaram com clareza a problemática da discriminação na sociedade e na escola. No entanto, tiveram dificuldade de assumir a sua própria responsabilidade nos processos de discriminação. Mesmo quando reconheceram as ações discriminadoras no interior da escola e, concretamente, as atitudes e os comportamentos docentes nessa perspectiva, em geral os situaram nos "outros". Os depoimentos reforçaram a afirmação da dificuldade da escola em lidar com essa problemática, mas, ao mesmo tempo, ofereceram uma diversidade de iniciativas, nas quais ficou clara a importância de se trabalhar a temática a partir de diversas dimensões.

\section{Construindo uma nova perspectiva para a educação escolar}

As questões relativas às relações entre educação escolar e cultura(s) são complexas e, como procuramos mostrar, afetam diferentes dimensões das dinâmicas educativas. Conseqüentemente, a formulação de um currículo multiculturalmente orientado não envolve unicamente introduzir determinadas práticas ou agregar alguns conteúdos, o que corresponderia apenas a uma abordagem que Banks (1999) intitula de "aditiva". Não basta acrescentar temas, autores, celebrações etc. É necessária uma releitura da própria visão de educação. É indispensável desenvolver um novo olhar, uma nova ótica, uma sensibilidade diferente. O caráter monocultural está muito arraigado na educação escolar, parecendo ser inerente a ela. Assim, questionar, desnaturalizar e desestabilizar essa realidade constitui um passo fundamental. Contudo, favorecer o processo de reinventar a cultura escolar não é tarefa fácil. Como afirmam os(as) educadores(as), exige persistência, vontade política, assim como aposta no horizonte de sentido: a construção de uma sociedade e uma educação verdadeiramente democráticas, construídas na articulação entre igualdade e diferença, na perspectiva do multiculturalismo emancipatório.

Para que se possa avançar nesse processo, o papel dos(as) professores(as) é fundamental. Nesse sentido, a formação docente, tanto a inicial como a continuada, passa a ser um locus prioritário para todos aqueles que queremos promover a inclusão destas questões na educação. No entanto, essa preocupação está ainda muito pouco presente nesses processos, ainda que se venha dilatando o espaço que tem conquistado nas diferentes instituições formadoras.

Nas experiências que temos desenvolvido, tanto em cursos de licenciatura e pós-graduação quanto em seminários, oficinas e assessorias às escolas públicas e particulares, consideramos que alguns elementos, a seguir apresentados, são fundamentais.

Um primeiro aspecto é partir de uma visão ampla da problemática, em que se analisem os desafios que uma sociedade globalizada, excludente e multicultural propõe hoje para a educação. O marco contextual é fundamental para que se possa construir o novo olhar que desejamos.

Outra questão importante é favorecer uma reflexão de cada educador(a) sobre a sua própria identidade cultural: como é capaz de descrevê-la, como tem sido construída, que referentes têm sido privilegiados e por meio de que caminhos. Temos desenvolvido várias vezes este exercício com os(as) educadores(as) e, em geral, o processo tem-se revelado muito provocador e instigante. Os níveis de autoconsciência da própria identidade cultural encontram-se, na maior parte das vezes, pouco presentes e não costumam constituir objeto de reflexão pessoal.

Muitos(as) profissionais da educação nos têm afirmado, em diversos momentos, que a primeira vez 
em que haviam parado para pensar sobre essa temática tinha sido por ocasião dos exercícios propostos, que certamente mobilizaram memórias, emoções e experiências. Em muitos casos, os exercícios fizeram aflorar histórias de vida, fortemente dramáticas, em que as questões culturais geraram muito sofrimento. Os relatos de discriminação e preconceito, reprimidos e silenciados por longo tempo, mostraram-se, então, particularmente fortes. Expressar-se, dizer sua palavra, tem um efeito profundamente libertador, permitindo que a experiência do "outro" se aproxime da nossa.

Também o aprofundamento da temática da formação cultural brasileira se faz imprescindível. Ainda está presente no imaginário coletivo o chamado "mito da democracia racial". Questionar os lugares comuns, as leituras hegemônicas da nossa cultura e de suas características, assim como das relações entre os diferentes grupos sociais e étnicos, constitui outro aspecto que carece discutir e aprofundar.

Na medida das possibilidades, outro ponto a ser trabalhado é a interação com diferentes grupos culturais e étnicos. A intenção é propiciar uma interação reflexiva, que incorpore uma sensibilidade antropológica e estimule a entrada no mundo do "outro".

Consideramos que todos esses aspectos são importantes, na formação docente, para que melhor se analisem as questões curriculares e a dinâmica interna da escola. O principal propósito, acrescentamos, é que o docente venha a descobrir outra perspectiva, assentada na centralidade da cultura, no reconhecimento da diferença e na construção da igualdade. Esperamos, assim, formar educadores que atuem como agentes sociais e culturais a serviço da construção de sociedades mais democráticas e justas.

ANTONIO FLAVIO BARBOSA MOREIRA doutorou-se em Educação no Instituto de Educação da Universidade de Londres. É professor da Universidade Católica de Petrópolis e Pesquisador Associado da Faculdade de Educação da UFRJ, onde coordena o Núcleo de Estudos de Currículo. Publicou diversos artigos sobre currículo e formação de professores, bem como o livro Currículos e programas no Brasil (Papirus, 1990). Organi- zou as seguintes coletâneas: Conhecimento educacional e formação do professor (Papirus, 1994); Currículo: questões atuais (Papirus, 1999) e Currículo: políticas e práticas (Papirus, 1999). Com Tomaz Tadeu da Silva, organizou Curículo, cultura e sociedade (Cortez, 1994) e Territórios contestados: o currículo e os novos mapas políticos e culturais (Vozes, 1995). Com Ana Canen, organizou Ênfases e omissões no currículo (Papirus, 2001). E-mail: afmcju@infolink.com.br

VERA MARIA CANDAU doutorou-se em Educação pela Universidade Complutense de Madrid (Espanha). É professora titular do Departamento de Educação da Pontifícia Universidade Católica do Rio de Janeiro. Assessora diversos programas socioeducativos em diferentes países latino-americanos. Tem desenvolvido vários estudos nas áreas de didática, formação de professores e, mais recentemente, com o apoio do CNPq e da FAPERJ, uma linha de pesquisa sobre "Cotidiano, Educação e Cultura(s)". Algumas das últimas publicações que organizou são: Reinventar a escola (Rio de Janeiro: Vozes, 2000), Sociedade, educação e cultura(s): questões e propostas. (Rio de Janeiro: Vozes, 2002) e Discriminación, sociedad y escuela en América Latina (Bolívia: Runa, 2002).E-mail:vmfc@edu.puc-rio.br

\section{Referências bibliográficas}

APPLE, Michael W., (1999). Power, meaning and identity: essays in critical educational studies. New York: Peter Lang.

BANKS, James, (1999). An introduction to multicultural education. Boston: Allyn and Bacon.

CANDAU, Vera Maria (org.), (2003). Somos tod@s iguais? Escola, discriminação e educação em direitos humanos. Rio de Janeiro: DP\&A.

CONNELL, Robert W., (1993). Schools and social justice. Montréal: Our Schools/Our Selves Education Foundation.

FEATHERSTONE, Mike, (1997). O desmanche da cultura : globalização, pós-modernismo e identidade. São Paulo: Studio Nobel.

GARCÍA CANCLINI, Néstor, (1990). Culturas híbridas : estratégias para entrar y salir de la modernidad. México: Grijalbo.

GIMENO SACRISTÁN, José, (2001). A educação obrigatória. Porto Alegre: Artmed.

GIROUX, Henry A., (1983). Theory and resistance in education: a pedagogy for the opposition. London: Heinemann. 
HALL, Stuart, (1997). A centralidade da cultura: notas sobre as revoluções de nosso tempo. Educação \& Realidade, v. 22, $\mathrm{n}^{\circ} 2$, p. $15-46$.

KRUEGER, Richard, CASEY, Mary Anne, (2000). A focus group: a practical guide for applied research. California: Sage Publications.

McCARTHY, Cameron, (1998). The uses of culture: education and the limits of ethnic affiliation. New York: Routledge.

ORTIZ, Renato, (1994). Mundialização e cultura. São Paulo: Brasiliense.

PEREZ GÓMEZ, Angel, (1998). La cultura escolar en la sociedad neoliberal. Madrid: Morata.

SARLO, Beatriz,(1999). Escenas de la vida posmoderna: intelectuales, arte y videocultura em la Argentina. Buenos Aires: Ariel.
SOUSA SANTOS, Boaventura, (2001). Dilemas do nosso tempo: globalização, multiculturalismo, conhecimento. Educação \& Realidade, v. 26, $\mathrm{n}^{\mathrm{o}} 1$, p. 13-32. , (2003). Reconhecer para libertar. Rio de Janeiro: Civilização Brasileira.

STOER, Stephen. R., CORTESÃO, Luiza, (1999). Levantando a pedra: da pedagogia inter/multicultural às políticas educativas numa época de transnacionalização. Porto: Afrontamento.

WILLINSKY, John, (1998). The educational politics of identity and category. Interchange, v. $29, \mathrm{n}^{\circ} 4$, p. 385-402.

Recebido em fevereiro de 2003 Aprovado em março de 2003 